\title{
A Contrastive Analysis of English and Turkish Plural Markers
}

\author{
Engin Evrim Önem ${ }^{1}$ \\ ${ }^{1}$ School of Foreign Languages, Erciyes University, Kayseri, Turkey \\ Correspondence: Engin Evrim Önem, School of Foreign Languages, Erciyes University, Kayseri, Turkey. Tel: \\ 9-0352-207-6666. E-mail: eonem@erciyes.edu.tr
}

Received: April 27, 2016 Accepted: May 20, 2016 Online Published: July 13, 2016

doi:10.5539/ijel.v6n4p112 URL: http://dx.doi.org/10.5539/ijel.v6n4p112

\begin{abstract}
This morphophonemic study aims to analyze pluralization processes for common nouns in English and native Turkish. To achieve this, a contrastive analysis focusing on English and Turkish plural markers from a structuralist point of view is taken. The results of the analysis reveal the differences and similarities between two languages in terms of plural markers. As for the differences, it is found that English and Turkish differ in regular and irregular plural forms as well as active role of consonants and vowels for pluralization process. Similarities for plural markers include focusing on the final sound of nouns, relying on distinctive features of sounds, employing allomorphs and using plural markers as suffixes for both languages to a varying degree. The findings of this study might help learners of English and Turkish by revealing the differences and similarities in both languages.
\end{abstract}

Keywords: English, Turkish, common nouns, plural markers, differences, similarities

\section{Introduction}

It is well known that most languages differentiate among parts of speech and languages have different systems and rules for each one of them. Nouns can be considered as an important part of a language since they affect other parts of speech of a language. For example, singularity or plurality of nouns has a direct effect on verbs in most languages and therefore, most languages have a distinction between singular and plural nouns. As a result, languages have included distinctive methods for pluralizing common nouns. For instance, while some languages such as German rely on articles and inflections, nouns in Japanese are not inflected and are deduced from the context. The differences might arise from the relatedness of languages. For example, English is a synthetic language (Trask, 1999) and like German, uses inflections for pluralization. On the other hand, as Csato \& Johanson (1998) mentioned, "Turkish is the most widely spoken member of the Oghuz branch of Turkic" (203) and thus shares the common characteristics of Turkic, which is different than Indo-European languages. For instance, Turkish is an agglutinative language, relying on different morphemes with specific roles and remaining unchanged after being added to other morphemes (Uzun, 2006). In this sense, it might be suspected that two unrelated languages like English and Turkish have different pluralization processes for common nouns. However, although studies dealing with pluralization processes in English and Turkish can be found separately for language learning purposes generally, there has not been a thorough comparison in the literature regarding this issue.

This study aims to reveal the differences and similarities between English and Turkish in terms of pluralizing common nouns using plural markers. To do this, a comparative analysis is made after presenting the fundamental rules for pluralization processes in both languages. Yet, as English has two different types of pluralization for common nouns, irregular and regular, only the regular form of pluralizing is focused on in the present study since Turkish does not have such an irregularity issue. Therefore, first, since English consonants are actively involved in pluralization process (Trask, 1999), English consonants and their distinctive features are briefly presented. Then, plural markers in English and rules for using plural markers are exemplified. After that section, as vowel harmony is at work during pluralization processes in Turkish (Göksel \& Kerslake, 2005), the proceeding section presents distinctive features of vowels and plural markers in Turkish along with the rules of pluralization. After a brief methodology section, the following section includes the contrastive analysis of both languages in terms of plural markers. Conclusion of the research and implications are given in the final section. 


\section{Consonants in English}

Although the difference in terms of manner and place of articulation is important, a consonant's being voiced or voiceless is the key factor for the plural markers in English (Trask, 1999). Therefore, the distinctive features of consonants should be studied first for pluralizing common nouns in English.

Like consonants of most languages, English consonants can be classified according to manner and place of articulation as well as being voiced or voiceless (unvoiced) (Radford et al., 2009). Distinctive features of consonants in English are presented in Table 1.

Table 1. Distinctive features of English consonants

\begin{tabular}{|c|c|c|c|c|c|c|c|c|c|}
\hline & \multicolumn{9}{|c|}{ Place of Articulation } \\
\hline \multirow{13}{*}{ 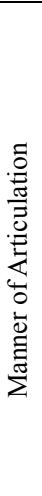 } & \multirow{3}{*}{ Stop } & & Bilabial & Labiodental & Interdental & Alveolar & Palatal & Velar & Glottal \\
\hline & & Voiceless & $\mathrm{P}$ & & & $\mathrm{t}$ & & $\mathrm{k}$ & $?$ \\
\hline & & Voiced & B & & & $\mathrm{d}$ & & $\mathrm{g}$ & \\
\hline & Nasal & Voiced & $\mathrm{m}$ & & & $\mathrm{n}$ & & $\eta$ & \\
\hline & \multirow{2}{*}{ Fricative } & Voiceless & & $\mathrm{F}$ & $\theta$ & $\mathrm{s}$ & $\int$ & & $\mathrm{h}$ \\
\hline & & Voiced & & V & ð & $\mathrm{z}$ & 3 & & \\
\hline & \multirow{2}{*}{ Affricate } & Voiceless & & & & & $\mathfrak{t}$ & & \\
\hline & & Voiced & & & & & ds & & \\
\hline & \multirow{3}{*}{ Glide } & Voiceless & $M$ & & & & & $M$ & \\
\hline & & Voiced & $\mathrm{w}$ & & & & $\mathrm{j}$ & w & \\
\hline & & Voiced & & & & & & & \\
\hline & \multirow[t]{2}{*}{ Liquid } & Central & & & & $\mathrm{r}$ & & & \\
\hline & & Lateral & & & & 1 & & & \\
\hline
\end{tabular}

Note. Adapted from Fromkin et al., 2011, p. 205.

Among other distinctive features of the consonants of English, the final consonant's being voiced or voiceless has an important role since the plural marker is chosen accordingly.

\subsection{Plural Markers in English}

Of the most common type of pluralizing, $-(e)_{S}$ is used as a suffix for pluralizing regular common nouns in English. However, due to phonological constraints, -(e)s undergoes allomorphy and appears as [s], [z] or [əz]/[rz] (Radford et al., 2009, p. 155). Examples of such allomorphy can be seen in Table 2.

Table 2. Examples of plural marker allomorphy in English

\begin{tabular}{|c|c|c|c|c|}
\hline Noun & Pronunciation & Pl. Noun & Allomorph & Pronunciation \\
\hline cat & kct & cats & $-\mathrm{s}$ & kcts \\
\hline tap & $\mathrm{t} \Subset \mathrm{p}$ & taps & $-s$ & tœps \\
\hline card & kard & cards & $-\mathrm{z}$ & kardz \\
\hline $\operatorname{dog}$ & dag & $\operatorname{dogs}$ & $-\mathrm{z}$ & $\operatorname{dagz}$ \\
\hline glass & gles & glasses & $-\mathrm{IZ}$ & glđEsIz \\
\hline watch & wats & watches & $-I Z$ & watfiz \\
\hline
\end{tabular}

The reason for allomorphy depends on the distinctive features of consonants in English, primarily, the voiced or voiceless distinction. Depending on the consonant in the final position of a noun, regular form of pluralizing varies among the allomorphs of -(e)s. If the final consonant is voiceless, then the allomorph [s] is used, as it is seen in the first two examples of cat and tap. However, if the final consonant is voiced, the allomorph used for pluralizing changes to [z], as in the examples of cards and dogs. In addition to these rules, manner of articulation is also in effect in some cases. For instance, depending on the manner of articulation, when the final consonant of a noun is either fricative or affricate, [Iz] is used to pluralize the noun in English as in glass and watch.

\subsection{Plural Markers and Assimilation}

Apart from voiced and voiceless difference and manner of articulation to affect the plural morphemes and allomorphs, another rule in effect for pluralizing regular nouns is the assimilation of consonants, which depends on the voiced and voiceless differences again. Fromkin et al. (2011, p. 529) define assimilation as "an ease of articulation process in which one sound influences the pronunciation of an adjacent or nearby sound." In other 
words, assimilation of consonants depends on one sound to affect the pronunciation of another sound to make it easier to produce. Examples of plural markers and assimilation can be seen in Table 3 .

Table 3. Examples of plural markers and assimilation in English

\begin{tabular}{|c|c|c|c|c|}
\hline Noun & Pronunciation & Pl. Noun & Allomorph & Pronunciation \\
\hline knife & naif & knives & $-\mathrm{z}$ & naIvz \\
\hline wife & waif & wives & $-\mathrm{z}$ & waIvz \\
\hline wolf & wolf & wolves & $-\mathrm{z}$ & wolvz \\
\hline identity & ardentrti & identities & $-\mathrm{z}$ & aIdentitiz \\
\hline university & ju:nıv3:siti & universities & $-\mathrm{z}$ & ju:nIv3:sıtiz \\
\hline dictionary & $\operatorname{dik} \int(\partial) n(\partial) r i$ & dictionaries & $-\mathrm{z}$ & $\operatorname{dik} \int(\partial) n(\partial) \operatorname{riz}$ \\
\hline
\end{tabular}

As it can be seen in Table 3, there are two examples for assimilation of regular pluralizing process in English. First rule is the change of a voiceless consonant to a voiced consonant. For example, as it is seen in knife, wife and wolf, a noun ending with voiceless fricative /f/ changes into voiced /v/ when pluralized first. Then, as with other cases of words ending with voiced sounds, [z] allomorph is used as in knives, wives and wolves.

The other rule is valid for the common nouns ending with $/ \mathrm{i} /$, as they are shown in the final three examples in the table above: identity, university and dictionary. The difference here between the first three and the second three examples is based on the ending of the word with a vowel instead of a consonant. Since vowels are voiced, as with other common nouns ending with voiced consonants, allomorph [z] is used in English as it can be seen in identities, universities and dictionaries.

\section{Vowels in Turkish}

When the number of vowels in all languages are considered, Turkish can be called as a "rich language" since it accommodates eight of the thirteen vowels found in all languages (Aksan, 2005). For the production of vowels of Turkish, a distinction among the height and the frontness of the tongue and roundness of the lips should be taken into consideration. Therefore, vowels of Turkish with their distinctive features should be analyzed first. Vowels of Turkish can be seen in Table 4.

Table 4. Vowels of Turkish

\begin{tabular}{lllll}
\hline & High & & $\begin{array}{l}\text { Non-High } \\
\text { (mid and low) }\end{array}$ & \\
\hline \multirow{3}{*}{ Front } & Rounded & Unrounded & Rounded & Unrounded \\
Back & ü & $\mathrm{i}$ & $\ddot{0}$ & $\mathrm{e}$ \\
\hline
\end{tabular}

Note. Göksel \& Kerslake, 2005, p. 9.

Vowels are important actors in native Turkish morphophonemics especially when it comes to syllables and suffixes. Turkish has six different syllable patterns (V, CV, VC, CVC, VCC and CVCC) and every syllable pattern includes one vowel (Özsoy, 2004). In fact, as mentioned by Göksel \& Kerslake (2005), most suffixes in Turkish are variable in form according to the rules of vowel harmony. All Turkish syllables contain one vowel and vowels have a certain effect on the proceeding vowels and suffixes (Uzun, 2006). In this sense, vowels can be called as the building blocks of syllables in Turkish and vowel harmony is one of the powerful rules of Turkish to govern phonological constraints.

\subsection{Vowel Harmony in Turkish}

Yavuz (2011) defines vowel harmony as a type of assimilation between neighbor vowels. In another word, it is the effect of previous vowel on the proceeding vowel. In fact, Göksel \& Kerslake (2005, p. 21) consider vowel harmony as "a phonological process which determines what vowel will appear in all but the first syllable of a word." Therefore, every suffix containing a vowel needs to comply with the vowel harmony rule in Turkish.

The constraints of sequencing vowels in native Turkish are defined by vowel harmony. In other words, vowel harmony limits the vowels to follow the preceding vowels in a word and sets the sequences. Vowel harmony is based on frontness of the tongue and roundness of the lips and two processes related to these features shape the vowel harmony. The first process is called as fronting harmony, which requires "the assimilation of a vowel with 
the vowel in the preceding syllable in terms of frontness" (Göksel \& Kerslake, 2005, p. 21). In other words, only a front vowel can be used after a front vowel or only a back vowel can be used after a back vowel. The second process of vowel harmony depends on "the assimilation of a vowel with the vowel in the preceding syllable in terms of roundedness" (Göksel \& Kerslake, 2005, p. 22), which is also called as rounding harmony. This rule includes round vowels to follow round vowels and unrounded vowels to follow unrounded only. These processes allow a certain group of vowel sequences in native Turkish to be permissible. Permissible vowel sequences in native Turkish are presented in Table 5 .

Table 5. Permissible vowel sequences in native Turkish

\begin{tabular}{|c|c|c|c|}
\hline \multirow{5}{*}{ Back vowels } & $/ \mathrm{a} /$ & can only be followed by & $/ \mathrm{a} /$ or $/ \mathrm{l} /$ \\
\hline & $/ 1 /$ & can only be followed by & $/ \mathrm{a} /$ or $/ 1 /$ \\
\hline & $/ 0 /$ & can only be followed by & $/ \mathrm{a} /$ or $/ \mathrm{u} /$ \\
\hline & $/ \mathrm{u} /$ & can only be followed by & $/ \mathrm{a} /$ or $/ \mathrm{u} /$ \\
\hline & /e/ & can only be followed by & /e/ or /i/ \\
\hline \multirow{3}{*}{ Front vowels } & $/ \mathrm{i} /$ & can only be followed by & /e/ or /i/ \\
\hline & /ö/ & can only be followed by & /e/ or / /ü/ \\
\hline & /ü/ & can only be followed by & /e/ or /ü/ \\
\hline
\end{tabular}

Note. Göksel \& Kerlslake, 2005, p. 21.

When a morpheme in Turkish include a back vowel like /a/, the permissible sequencing is limited to morphemes including $/ \mathrm{a} /$ and $/ 1 /$. On the other hand, when the preceding vowel in a morpheme is a front vowel such as /ö/, the only allowed sequencing include either /e/ or / ̈/ for the following morphemes. Some examples of vowel harmony in Turkish depending on these processes are given in Table 6.

Table 6. Examples of vowel harmony

\begin{tabular}{lllll}
\hline Turkish Word & English Word & $\begin{array}{l}\text { Phonetic } \\
\text { Transcription }\end{array}$ & Root and suffixes & $\begin{array}{l}\text { Distribution of } \\
\text { suffixes }\end{array}$ \\
\hline evlerim & my houses & evlerim & ev - ler - i - m & house - plural - blending vowel - case marker \\
kapıcı & door man & kapıḑı & kap1 - c1 & door - derivation \\
uçaklar & planes & utfaklar & uçak - lar & plane - plural \\
üzüntülü & sorrowful & üzüntülü & üzüntü - lü & sorrow - post position (-ful) \\
\hline
\end{tabular}

As it can be seen in the examples, except for a few exceptions (see Göksel \& Kerlslake, 2005 for the list), every suffix in native Turkish needs to comply with vowel harmony. For instance, since /e/ in $e v$ is an unrounded front vowel, only morphemes carrying /e/ or /i/ could be attached, as seen in the suffixes. Similarly, as /a/ in kapt is an unrounded back vowel and as the result of the permissible vowel sequences, suffix including $/ 1 /$ is employed. As seen, such constraints affect the plural marker.

\subsection{Plural Markers of Turkish}

Turkish is an agglutinative language and it assigns specific roles to specific morphemes (Uzun, 2006). In this sense, Turkish might be called to have a very strict rule based morphological system. Plural markers for common nouns are a good example of this morphological system.

Turkish plural marker is -lAr, which has two allomorphs: [ler] and [lar] (Csato \& Johanson, 1998). The allomorphs of -lAr differ only in vowels depending on the vowel harmony. Examples for plural markers of Turkish are presented in Table 7.

Table 7. Examples of plural markers

\begin{tabular}{lllll}
\hline & & Phonetic & & \\
Turkish Word & English Word & Transcription & Root and suffixes & Distribution of suffixes \\
\hline köpekler & dogs & köpekler & köpek - ler & dog - plural \\
arabalar & cars & arabalar & araba - lar & car - plural \\
kediler & cats & kediler & kedi - ler & kat - plural \\
kuşlar & birds & kuflar & kuş - lar & kuş - plural \\
\hline
\end{tabular}


When the examples are analyzed, it is quite obvious that vowel harmony plays an important role in sequencing plural markers in native Turkish. Utilizing allomorphs [ler] and [lar] depend on the vowel of the preceding syllable. When the preceding vowel in the syllable is a front vowel, [ler] is used. For example, when the vowel of the preceding syllable is /e/ or /i/, [ler] is used as in köpekler and kediler. On the other hand, when the vowel of the preceding syllable is a back vowel, [lar] is used as in araba and kuş; syllables containing /a/ or /u/.

However, of the two underlying processes of vowel harmony, fronting harmony seems to be dominantly involved in the case of plural markers than rounding harmony. As mentioned above in Table 5, there is only a limited number of permissible vowel sequences in Turkish. This is due to the low number of plural markers in Turkish. Since there are only two allomorphs for plural markers in Turkish, the rounding harmony process is not at work for pluralization process. Yet, hypothetically, if there were more allomorphs of - $l A r$ such as *[lor] or *[lör], rounding harmony might also be needed to be considered.

\section{Methodology}

The differences and similarities between English and Turkish for pluralizing common nouns are analyzed by comparing and contrasting the pluralization processes in each language within the light of rules presented above.

\section{Comparison of Pluralization Processes in English and Turkish}

The comparison between Turkish and English pluralization process for common nouns focusing on plural markers are given separately in different sub-sections. First, the differences are presented in the next sub-section and similarities are presented in the latter sub-section.

\subsection{Differences between English and Turkish}

\subsubsection{Regularity vs. Irregularity}

There are not any irregular plural nouns in native Turkish. In other words, all native Turkish common nouns undergo the same process of pluralization employing [ler] and [lar], allomorphs of - $l A r$ respectively according to the rules of pluralization. On the other hand, there is a distinction between regular and irregular nouns for pluralization process in English. Although most of the common nouns are pluralized by employing the allomorphs of $-(e) s,[\mathrm{~s}],[\mathrm{z}]$ or [-1z], according to the rules of pluralization (Yule, 2006), there is still a group of nouns with irregular plural forms in English.

\subsubsection{Consonants vs. Vowels}

In English, consonants have an active role in pluralizing the regular nouns. For instance, depending on the final consonant of a noun, one of the allomorphs of plural marker - $(e) s$ in English is used and distinctive features of the final consonant of the word permit a certain allomorph to be used as the plural marker. However, Turkish relies heavily on the vowels in terms of pluralizing. As mentioned above, depending on the frontness of the tongue or the roundness of the lips for the formation of the vowel in the final syllable, one of the allomorphs of plural marker - $l \mathrm{Ar}$ is used in Turkish.

\subsubsection{Assimilation of Consonants}

While pluralizing common nouns in English, plural markers have an effect on the final consonant of some common nouns ending with voiceless fricatives (e.g. knife). This effect leads to a change in the sound towards assimilation during pluralization and results in a change of the sound into a voiced fricative (e.g. knives). However, although assimilation of consonants do occur in Turkish in other affixation or word formation processes (see Göksel \& Kerslake, 2005), this is not seen in Turkish in terms of pluralization since Turkish relies on vowel harmony for pluralization.

\subsection{Similarities between English and Turkish}

\subsubsection{Final Sound of Nouns}

Although pluralization in English and Turkish differ in terms of their focus on consonants and vowels, both languages depend on the final sound of nouns. The final consonants' being voiced or voiceless and/or manner of articulation is important in English for plural markers. For instance, the final $/ \mathrm{r} /$ as in car only permits to [z] because of its being voiced. Similarly, the final or preceding vowel defines the allomorph for plural marking in Turkish. For example, /a/ in kask (helmet) can only be pluralized by attaching [lar] in Turkish because of the vowel harmony rule.

\subsubsection{Distinctive Features of Sounds}

Both English and Turkish make use of the distinctive features of sounds in terms of pluralization and employ allomorphs rather than introducing novel plural forms of words accordingly (except for the irregular nouns in 
English). Although English depends on consonants, their distinctive features, including being voiced or voiceless along with their manner of articulation are taken into consideration during pluralization processes. Turkish, on the other hand, depends on vowels, yet, pays attention to the position of tongue as well as the roundness and flatness of the lips for pluralization processes and employs allomorphs of plural morpheme accordingly.

\subsubsection{Suffixes}

Although English allows prefixes and suffixes to be used for word formation, native Turkish allows only suffixes. Yet, for pluralization processes, both languages use suffixes only and they employ different allomorphs of the plural markers.

\subsubsection{Multiple Uses of Plural Markers}

Plural marker - $(e)_{s}$ and its allomorphs can also be used as a marker for third person singular in simple present tense in English. For example, as in he drinks tea, drinks (drink $+3^{\text {rd }}$ person sing.) include the same morpheme used as plural marker. In other words, the plural morpheme has multiple uses with similar phonotactic requirements. Similarly, plural morpheme - $l A r$ can be used as third person plural marker as well in Turkish. For instance, in koşarlar (koş-a-r-lar/ they run), [lar] acts as a marker for the third person plural for simple present tense. However, although the $3^{\text {rd }}$ person plural marker can be ignored in Turkish as in koşar (koş-a-r/they run), the $3^{\text {rd }}$ person singular case marker cannot be ignored in English as he $*$ drink tea.

\section{Conclusion}

This paper aims to reveal the differences and similarities between English and Turkish in terms of plural markers and the pluralization processes. Contrastive analysis of both languages show that English and Turkish have different rules for the plural markers but similar pluralizing processes. Besides the regular and irregular plural form differences in English and Turkish, the differences depend heavily on the use of consonants and vowels. English relies on consonants and their distinctive features have important roles in terms of pluralizing common nouns. In this sense, it can be said that vowels do not have an active role like they do in Turkish. On the other hand, Turkish focuses on the vowel in the final syllable of a noun for pluralization processes and disregards the consonants. The similarities in pluralization processes of both languages are seen in the way plural markers and their allomorphs are attached to most common nouns as suffixes depending on the distinctive features of final sounds. Also, both languages employ the plural markers as personal markers for nouns as well, even though they are used for third person singular in English and third person plural in Turkish.

It can be inferred from the analysis that both English and Turkish have straightforward and clear cut rules for pluralization of common nouns. Yet, since as an agglutinative language, Turkish does not allow irregularities and each morpheme has a very specific role assigned. Also, Turkish orthography has a higher grapheme to morpheme and vice versa rate. In this sense, learning Turkish pluralization process and applying plural markers to common nouns might be considered relatively easier than English.

The findings of this study might help learners of English and Turkish by revealing the differences and similarities between both languages. Learners might be able to develop their strategies in terms of rule generating and applying them to language. As a result, if the underlying rules of pluralization can be understood, it would help learners to avoid the need for memorizing plural forms of common nouns in English and Turkish.

\section{References}

Abushihab, I. (2012). Morphological and lexical contrastive analysis of Turkish and English. Global Journal of Human Social Science, 12(1), 25-34.

Aksan, D. (2005). Türkçenin Gücü (9th ed.). Ankara: Bilgi Yayınevi.

Csato, E. A., \& Johanson, L. (Eds.) (1998). Turkish. The Turkic Languages (pp. 203-235). New York: Routledge.

Fromkin, V., Rodman, R., \& Hyams, N. (2011). An Introduction to Language (9th ed.). Canada: Cengage Learning.

Göksel, A., \& Kerslake, C. (2005). Turkish: A Comprehensive Grammar. New York: Routledge. http://dx.doi.org/10.4324/9780203340769

Özsoy, A. S. (2004). Türkçenin Yapısl—I Sesbilim. İstanbul: Boğaziçi Üniversitesi Yayınevi.

Radford, A., Atkinson, M., Britain, D., Clahsen, H., \& Spencer, A. (2009). Linguistics-An Introduction (2nd ed.). Cambridge: Cambridge University Press. http://dx.doi.org/10.1017/CBO9780511841613

Trask, R. L. (1999). Key Concepts in Language and Linguistics. New York: Routledge. 
Uzun, N. E. (2006). Biçibilim-Temel Kavramlar. Istanbul: Papatya.

Yavuz, H. (2011). Why study sounds? In Z. Balpinar (Ed.), Turkish Phonology and Morphology (pp. 2-13). Eskişehir: Anadolu University.

Yule, G. (2006). The Study of Language (3rd ed.). Cambridge: Cambridge University Press.

\section{Copyrights}

Copyright for this article is retained by the author(s), with first publication rights granted to the journal.

This is an open-access article distributed under the terms and conditions of the Creative Commons Attribution license (http://creativecommons.org/licenses/by/3.0/). 